\title{
TRATAMENTOS PRÉ-GERMINATIVOS EM SEMENTES DE ARAÇÁ-BOI (Eugenia stipitata) ${ }^{1}$
}

\author{
ANGELA MARIA DA SILVA MENDES² \& MARIA SÍLVIA DE MENDONÇA ${ }^{3}$
}

RESUMO - O araçá-boi (Eugenia stipitata) é uma fruteira nativa com grande potencial agroindustrial. Suas sementes são intolerantes ao dessecamento e apresentam dormência, o que dificulta sua propagação. O objetivo do trabalho foi analisar as características de germinação das sementes de araçá-boi submetidas a diferentes tratamentos pré-germinativos: retirada parcial do tegumento, lixiviação e fracionamento. A germinação das sementes intactas e com retirada parcial do tegumento foi realizada em dois ambientes: casa de vegetação e viveiro telado com sombrite de 50\%. Para a lixiviação, as sementes foram colocadas em balde e submetidas à lixiviação, em água corrente, por até 90 dias, com intervalos de 10 dias. O fracionamento das sementes foi realizado de acordo com a posição da zona meristemática de protrusão da raiz e parte aérea (fracionamento transversal e longitudinal). A retirada parcial do tegumento das sementes de araçá-boi diminui o tempo médio de germinação de 91 para 48 dias, com 100\% de emergência. As sementes de araçá-boi mantidas submersas em água corrente por até 50 dias mantêm a viabilidade e o vigor. As frações de sementes que apresentam a protuberância meristemática formam plântulas normais, com as mesmas características de germinação das sementes intactas, porém os diferentes tipos de fracionamento não aceleraram nem uniformizaram a germinação das sementes.

Termos para Indexação: dormência, fruteira nativa, sementes recalcitrantes.

\section{PRE-GERMINATIVE TREATMENTS IN ARAÇÁ-BOI SEEDS (Eugenia stipitata ssp. sororia McVaugh) - MYRTACEAE}

\begin{abstract}
The araçá-boi (Eugenia stipitata) is a native fruit tree with high agribusiness potential. Its seeds are intolerant of desiccation and present dormancy, which makes more difficult propagation. The objective of this study was to analyze the characteristics of araçá-boi seed germination with three pre-treatments to enhance germination: partial tegument removal, leaching and fractionation. The germination of intact seeds and seeds with partial tegument removal was done in two environments: greenhouse and screened nursery $(50 \%)$. For leaching, the seeds were placed in a bucket and subjected to leaching in running water (hose nozzle at the bottom of the bucket) for up to 90 days, with intervals of 10 days. The fractionation of seeds was performed according to the meristematic zone position of root and shoot protrusion (transverse and longitudinal fractionation). The partial tegument removal from the araçá-boi seeds decreased the period of germination from 91 to 48 days with $100 \%$ of emergence. The seeds of araçá-boi submerged in water for 50 days, maintains the viability and vigor. The fractioned seeds cut at the meristematic protuberance make normal seedlings, with the same characteristics of intact seed germination, but the other types of fractionation didn't speed up or make the seeds germinated uniformly.
\end{abstract}

Index terms: dormancy, native fruit, recalcitrant seeds.

${ }^{1}$ (Trabalho 277-11). Recebido em: 08-11-2011. Aceito para publicação em: 10-08-2012.

${ }^{2}$ Doutora pelo Programa de Pós-Graduação em Agronomia Tropical da Universidade Federal do Amazonas. R. Brigadeiro João Camarão, 39, Condomínio Solar dos Franceses, Torre Marseille, apto. 502, Dom Pedro. E-mail: amendes@ufam.edu.br

${ }^{3}$ Professora Dra. da Faculdade de Ciências Agrárias da Universidade Federal do Amazonas. Email: msilvia@ufam.edu.br 


\section{INTRODUÇÃO}

O araçá-boi (Eugenia stipitata ssp. sororia McVaugh) é uma espécie adaptada a solos de baixa fertilidade, assim como às variações climáticas do trópico úmido amazônico. Em decorrência da precocidade, frequência e grande volume de produção da planta, associados ao sabor característico e agradável da polpa do fruto, o araçá-boi destaca-se como uma das espécies nativas da Amazônia de grande potencial. Estudos realizados com a polpa de araçá-boi apontam grande potencial de aproveitamento agroindustrial, por apresentarem boas características físico-químicas e atributos sensoriais de boa aceitabilidade (ROGEZ et al., 2004). Schwartz et al. (2010) comentam que há uma demanda cada vez maior no mercado internacional por frutas com novos aromas, sabores e texturas e que o Brasil, em função de sua enorme biodiversidade e condições edafoclimáticas, é um país com imenso potencial para fornecer esses recursos naturais vegetais.

A dormência de sementes tem papel relevante para a perpetuação das espécies. Por outro lado, constitui-se em grande problema para a propagação em nível comercial, principalmente se a dormência for inerente à semente. Os fatores intrínsecos relacionados com a dormência de sementes são, principalmente, a dureza e a impermeabilidade do tegumento à água e aos gases, embrião imaturo e presença de inibidores da germinação (CARDOSO, 2004). Estudo realizado por Gentil e Ferreira (1999) revelou que o tegumento das sementes de araçá-boi apresenta restrição mecânica à expansão do embrião. Nesse estudo, os autores constataram que a retirada total do tegumento proporcionou maior porcentagem, velocidade e menor tempo médio de germinação, e que a retirada parcial do tegumento, no lado oposto ao rompimento do embrião, apresentou a mesma resposta germinativa das sementes intactas.

Algumas substâncias encontradas em sementes podem interferir no processo de germinação. Esses inibidores da germinação podem estar localizados em diferentes estruturas da semente. Para Sert et al. (2009), entre essas substâncias, destacam-se o ácido abscísico e os compostos fenólicos. Esses mesmos autores sugerem a lixiviação como método para a superação da dormência causada por esses inibidores. Espécies da família Myrtaceae são constantemente relacionadas como produtoras de compostos secundários, especialmente compostos fenólicos (PIETROVSKI et al., 2008; REYNERTSON et al., 2008).

O fracionamento de sementes de espécies do gênero Eugenia tem sido estudado no Brasil com o objetivo de maximizar a produção de mudas dessas frutíferas nativas. Esses estudos demonstram que é possível obter plântulas normais por meio de sementes fracionadas de E. pyriformis, E. involucrata, E. uniflora e E. brasiliensis (SILVA et al., 2003; SILVA et al., 2005). Estudos realizados por Anjos e Ferraz (1999) revelaram que as sementes de E. stipitata injuriadas na zona meristemática e sementes seccionadas ao meio são capazes de germinar e formar plântulas, porém não mencionam o tempo para cada fração germinar.

O objetivo do trabalho foi analisar as características de germinação das sementes de $E$. stipitata submetidas a diferentes tratamentos pré-germinativos.

\section{MATERIAL E MÉTODOS}

Os frutos foram coletados de 40 indivíduos estabelecidos no pomar do Setor de Produção da Faculdade de Ciências Agrárias da Universidade Federal do Amazonas. As sementes foram extraídas de frutos completamente maduros. A extração das sementes foi feita manualmente, seguida de lavagem em água corrente com auxílio de peneira, e foram colocadas para secar em temperatura ambiente com média de $25^{\circ} \mathrm{C}$ e umidade relativa do ar de $80 \%$, a fim de se retirar a umidade da superfície do tegumento das sementes. Uma amostra do lote foi retirada para a realização do teor de água inicial, que foi realizado com duas subamostras de $5 \mathrm{~g}$ de sementes pelo método de estufa a $105^{\circ} \mathrm{C}$ (BRASIL, 2009). Os experimentos foram realizados nas condições climáticas de Manaus, no período de julho de 2009 a outubro de 2010 (Figura 1).

\section{Experimento 1: retirada parcial do tegu- mento e germinação em dois ambientes}

A germinação das sementes intactas e com retirada parcial do tegumento foi realizada em dois ambientes: casa de vegetação com cobertura de plástico transparente utilizado na plasticultura e viveiro telado com sombrite de $50 \%$. O experimento constituiu-se dos seguintes tratamentos: T1 - sementes intactas, semeadas em casa de vegetação; T2 - sementes com retirada parcial do tegumento, semeadas em casa de vegetação; T3 - sementes intactas, semeadas em viveiro, com sombreamento de 50\%; e T4 - sementes com retirada parcial do tegumento, semeadas em viveiro, com sombreamento de $50 \%$. Os tratamentos foram arranjados em delineamento experimental inteiramente casualizado, sendo cada tratamento composto de cinco repetições de 20 sementes.

Para evitar injúrias mecânicas e facilitar a retirada parcial do tegumento, foi necessária a 
secagem das sementes por 16 horas em ambiente de laboratório. A retirada de parte do tegumento foi realizada com auxílio de bisturi na região da protrusão da raiz e parte aérea. As sementes foram semeadas em caixas plásticas $(55 \times 38 \times 9 \mathrm{~cm})$ contendo como substrato vermiculita de textura média.

A irrigação foi realizada diariamente e três vezes por semana avaliou-se a porcentagem de germinação, considerando como germinadas as sementes com a emergência do epicótilo. No final do experimento, aos 160 dias da semeadura, quando não foi mais observada a emergência das sementes em um intervalo de 20 dias, as mesmas foram separadas por tratamento e repetição, em quatro categorias, sendo: 1) plântulas normais (presença de raiz primária desenvolvida e parte aérea proporcional, ambas sem defeitos aparentes); 2) plântulas anormais (qualquer anomalia que descaracterize uma plântula normal); 3) sementes mortas (sementes deterioradas, sem sinal de protrusão de raiz e parte aérea), e 4) sementes viáveis (sementes com massa cotiledonar não deteriorada de aparência fresca, sem sinal de protrusão de raiz e parte aérea). Para avaliar as sementes mortas e intactas, as mesmas foram cortadas próximo à protuberância meristemática de protrusão da raiz e parte aérea.

\section{Experimento 2: lixiviação das sementes}

Após o beneficiamento, as sementes foram colocadas em balde com capacidade de 18 litros e submetidas à lixiviação em água corrente (bico da mangueira no fundo do balde) por até 90 dias. Foram utilizados dez tempos de lixiviação, com intervalos de 10 dias, compondo os seguintes tratamentos: T1sementes sem lixiviação (controle); T2- sementes lixiviadas por 10 dias; T3- 20 dias; T4- 30 dias; T5- 40 dias; T6- 50 dias; T7- 60 dias; T8- 70 dias; T9- 80, dias e T10- 90 dias.

Foi obtido o teor de água das sementes para cada tempo de lixiviação. A germinação das sementes foi realizada em viveiro, com $50 \%$ de sombreamento, em caixas plásticas $(55 \times 38 \times 9 \mathrm{~cm})$ contendo como substrato serragem decomposta, em delineamento experimental inteiramente casualizado, com dez tratamentos e quatro repetições de 10 sementes. A irrigação foi realizada diariamente, e duas vezes por semana avaliou-se a porcentagem de germinação, considerando como germinadas as sementes com a emergência do epicótilo.

Experimento 3: fracionamento das sementes

O fracionamento das sementes foi realizado com sementes recém-beneficiadas. Além do controle (sementes intactas), foram realizados dois tipos de fracionamento com auxílio de um bisturi. Os cortes foram realizados de acordo com a posição da zona meristemática de protrusão da raiz e parte aérea (Figura 2), no constituindo-se os seguintes tratamentos: T1 - sementes intactas; T2 - lado da rafe (as sementes foram cortadas ao meio sentido longitudinal, formando duas metades); T3 - lado oposto à rafe (a outra metade do tratamento 2); T4 - lado da protuberância meristemática (as sementes foram cortadas ao meio no sentido transversal, formando duas metades), e T5 - lado oposto à protuberância meristemática (a outra metade do tratamento 4).

A germinação das sementes foi realizada em casa de vegetação. As sementes ou frações foram semeadas em bandejas plásticas $(55 \times 38 \times 9$ $\mathrm{cm})$ contendo como substrato serragem curtida, em delineamento experimental inteiramente casualizado, com cinco tratamentos e quatro repetições de 20 sementes ou frações. Duas vezes por semana, a germinação foi avaliada, anotando-se as sementes ou frações com a formação da plântula, ou seja, expansão do primeiro par de e ofilo. No final do experimento, aos 220 dias da semeadura, quando não se observou emergência, os propágulos foram separados por tratamento e repetição, em três categorias: plântulas normais (estas caracterizadas pela presença de raiz primária desenvolvida e parte aérea proporcional ao tamanho da raiz primária, ambas sem defeitos aparentes, produzidas a partir de cada semente ou fração de semente), plântulas anormais (qualquer anomalia que descaracterize uma plântula normal), e sementes ou frações mortas (sementes ou frações deterioradas sem sinal de protrusão de raiz e parte aérea).

As características avaliadas em todos os experimentos foram: emergência (\%), tempo médio de emergência (dia), velocidade média de emergência $\left(\right.$ dia $\left.^{-1}\right)$ e velocidade de emergência (planta/dia), seguindo as recomendações de Santana e Ranal (2004). Os dados foram submetidos aos testes de Shapiro-Wilk (normalidade dos resíduos) e de Levene (homogeneidade entre as variâncias). Os resíduos apresentaram distribuição normal, e às variâncias homocedásticas, então, foi aplicada a análise de variância (ANOVA), seguida do teste de Tukey, a $5 \%$ de probabilidade.

\section{RESULTADOS E DISCUSSÃO}

\section{tegumento}

\section{Experimento 1: retirada parcial do}

Aos 160 dias após a semeadura, observouse diferença significativa entre os tratamentos para 
todas as características avaliadas (Tabela 1$)$.

Gentil e Ferreira (1999), estudando escarificação mecânica em sementes de araçáboi, obtiveram valores relativamente inferiores, principalmente para tempo médio de germinação, com os tratamentos de retirada do tegumento de um lado (83\% de emergência e 90 dias de tempo médio de germinação) e retirada total do tegumento (96\% de emergência e 66 dias de tempo médio de germinação), em ambiente de viveiro com 50\% de sombreamento. Observou-se, neste experimento, que as sementes com retirada parcial do tegumento, semeadas em viveiro com 50\% de sombreamento, apresentaram $100 \%$ de emergência com tempo médio de 48 dias (Tabela 1). Alguns fatores podem ter contribuído para tais diferenças, como o tempo de secagem para proceder à retirada do tegumento, e injúrias profundas causadas no momento da retirada do tegumento.

A retirada total do tegumento das sementes de araçá-boi é de difícil manuseio, pois as sementes consistem em um tegumento externo com consistência papirácea “papelão”, tegumento interno cartáceo (quebradiço) lignificado e um grande embrião conferruminado, passivo de injúrias (MENDES, 2011). Além disso, a semente de araçá-boi possui uma protuberância meristemática superficial que, quando injuriada, pode regenerar, como observado por Gentil e Ferreira (1999), mas também pode atrasar a germinação ou formar plântulas anormais. Portanto, injúrias mecânicas no embrião devem ser evitadas, e a retirada apenas parcial do tegumento facilitará o manuseio das sementes por parte dos viveiristas.

O ambiente de germinação influenciou na formação de plântulas normais de araçá-boi, principalmente as sementes com a retirada parcial do tegumento e semeadas em casa de vegetação, onde se observaram 32\% de plântulas anormais (Figura 3) e $98 \%$ de emergência (Tabela 1). Provavelmente, o principal fator dessas anomalias foi o aumento da temperatura ambiente e a incidência de luz solar direta na casa de vegetação. As altas temperaturas prejudicaram a protuberância meristemática do embrião, exposta ao substrato pela retirada do tegumento, causando anomalias nas plântulas. As principais anomalias foram a emissão de dois epicótilos na mesma área de protrusão, apesar de a semente ser monoembriônica, emissão de epicótilo atrofiado e emissão de epicótilo sem emissão de raiz.

Justos et al. (2007), estudando diferentes temperaturas na germinação de E. pyriformis, observaram que, na maior temperatura $\left(30^{\circ} \mathrm{C}\right)$, houve $100 \%$ de germinação, porém apenas 31\% formaram plântulas normais. Os autores afirmam que, nessa temperatura, ocorreu emergência de parte aérea, mas os epicótilos não se desenvolviam devido ao escurecimento e à deterioração. Porém, Martinotto et al. (2007) observaram maiores anomalias em plântulas de E. dysinterica, cultivadas in vitro, em sementes com tegumento. Os autores supracitados também observaram que a retirada total do tegumento reduziu o tempo médio de germinação para esta espécie.

\section{Experimento 2: lixiviação das sementes}

A lixiviação, em água corrente, favoreceu a germinação das sementes de araçá-boi, até 40 dias, havendo redução no tempo médio de emergência, de 107 dias, sem lixiviação, para 70 dias, com 40 dias de lixiviação, e aumento da velocidade média e índice de velocidade de emergência (Tabela 2).

Alguns compostos presentes na semente de araçá-boi podem contribuir para a demora da germinação. O tegumento das sementes de araçá-boi apresenta compostos fenólicos de natureza diversa, principalmente tanino, além de terpenoides com grupo carbonila e a epiderme adaxial do embrião apresenta numerosos idioblastos fenólicos (MENDES, 2011).

Até os 50 dias de lixiviação, a viabilidade e o vigor das sementes foram mantidos, e a partir dos 60 dias, o vigor das sementes foi afetado, porém, ainda, com 50\% de emergência, aos 90 dias de lixiviação. Observa-se, na Tabela 2, que não houve diferença significativa para a porcentagem de germinação entre os períodos de zero até 70 dias de lixiviação. Também foi observado que até os 50 dias de lixiviação, houve redução do tempo médio de germinação. Isto indica que a redução no tempo médio de germinação é decorrente do fato de que as sementes, antes de serem semeadas, já haviam iniciado o processo de germinação. Mendes (2011) observou, em sementes de araçá-boi, que os processos fisiológicos de maturação continuam após a dispersão. Neste experimento, pôde-se observar que o processo maturação-germinação também é contínuo. É provável que o teor de água, no período de lixiviação, já esteja dentro daqueles que caracterizam a fase II do padrão trifásico da embebição, ou seja, a água é absorvida, lentamente, e não ocorre crescimento do eixo embrionário.

A perda de vigor, a partir de 60 dias de lixiviação, está relacionada com a deterioração das sementes. Na Figura 4, pode-se observar que o teor de água durante a lixiviação aumentou continuamente e, aos 50 dias de lixiviação, esse acréscimo no teor de água das sementes foi acentuado. Substâncias de reservas podem ter sido lixiviadas ou gastas nesse 
período, o que pode ter refletido na perda de vigor das sementes. Portanto, a perda de substâncias de reservas, durante a lixiviação, deve ser monitorada no decorrer do estudo.

A lixiviação em água corrente, nas sementes de araça-boi, também favoreceu a conservação das sementes por períodos mais longos. Além disso, o tempo de armazenamento na água diminuiu o tempo médio de germinação. Scalon et al. (2012) observaram redução do tempo médio de germinação em sementes de E. pyriformes, de 66 para 40 dias, quando estas, foram submetidas ao armazenamento por 30 dias.

\section{mentes}

Experimento 3: fracionamento das se-

A germinação das sementes fracionadas foi avaliada até aos 220 dias após a semeadura. Todas as frações foram capazes de formar plântulas normais (Figura 5), porém a porcentagem de plântulas normais foi baixa para as frações que não apresentavam a protuberância da zona meristemática. As médias de porcentagem de plântulas normais e o índice de velocidade de emergência foram, significativamente, superiores para os tratamentos, onde as sementes ou frações apresentavam a protuberância meristemática (Tabela 3).

Apesar de o tecido embrionário das sementes de araçá-boi apresentar capacidade regenerativa e polaridade semelhante aos caules das plantas (totipotência), esses mecanismos processam-se de forma ainda mais lenta que a germinação das sementes intactas, mesmo que a barreira mecânica seja removida com os fracionamentos. Além disso, houve maior possibilidade de formação de plântulas anormais (Tabela 3).

Para a espécie E. pyriformis, é possível obter plântulas normais e com alta porcentagem de germinação, em até oito frações da semente, sendo que os melhores desempenhos de germinação foram das frações de corte longitudinal (SILVA et al., 2003). No entanto, para as espécies E. involucrata, E. uniflora e E. brasiliensis, as frações devem conter, pelo menos, metade do hilo para se obter altas porcentagens de germinação (SILVA et al., 2005).

Silva et al. (2005) citam, para E. involucrata, E. uniflora e E. brasiliensis, a presença de hilo, sendo este a área de emergência da plântula, sem mencionar o eixo embrionário. Em E. stipitata, o eixo não está diferenciado, mas observa-se uma protuberância meristemática, onde ocorre a protrusão da raiz e da parte aérea. Nas frações que não continham esse tecido, também houve formação de plântulas, sugerindo haver tecido meristemático em outras partes do embrião. Nos tratamentos 2 e 4, a germinação ocorreu na protuberância meristemática como nas sementes intactas; no tratamento 3 (lado oposto à rafe e protuberância meristemática), a germinação ocorreu na linha de soldadura dos cotilédones na área seccionada, e, no tratamento 5, a germinação ocorreu na face seccionada, porém na extremidade que continha parte da rafe (Figura 2). Anjos e Ferraz (1999) observaram as mesmas características de germinação do tratamento 5 .

Fica claro que, apesar de o fracionamento das sementes de E. stipitata proporcionarem plântulas normais, não houve uniformização nem acelerou a formação de plântulas normais, pois o tempo e a velocidade de emergência foram semelhantes aos das sementes intactas. As frações que não apresentam a região meristemática requerem mais tempo para formar essa zona, que se assemelha a um botão germinativo, havendo a diferenciação dos meristemas apicais radicular e caulinar. Pelas características de germinação apresentadas pela espécie, podem-se sugerir estudos de propagação in vitro, a partir de embriões zigóticos.

TABELA 1 - Médias das características de emergência de plântulas de araçá-boi submetidas à retirada parcial do tegumento, em casa de vegetação e viveiro, com sombreamento de 50\%, após 160 dias da semeadura. Manaus-AM, 2010.

\begin{tabular}{|c|c|c|c|}
\hline \multirow{5}{*}{$\begin{array}{c}\text { T1 - Sementes intactas (casa de vegetação) } \\
\text { T2 - Retirada parcial do tegumento } \\
\text { (casa de vegetação) }\end{array}$} & \multicolumn{3}{|c|}{ Características } \\
\hline & Emergêncic & dade de emergência & Tempo médio \\
\hline & $(\%)$ & (planta/dia) & de emergência (dia) \\
\hline & $78,0 \mathrm{ab}$ & 0,098 b & $87,0 \mathrm{~b}$ \\
\hline & $98,0 \mathrm{a}$ & $0,230 \mathrm{a}$ & $46,0 \mathrm{a}$ \\
\hline $\begin{array}{c}\text { T3 - Sementes intactas } \\
\text { (viveiro 50\% sombreamento) }\end{array}$ & $66,0 \mathrm{~b}$ & 0,078 b & $91,0 \mathrm{~b}$ \\
\hline $\begin{array}{l}\text { T4 - Retirada parcial do tegumento } \\
\text { (viveiro } 50 \% \text { sombreamento) }\end{array}$ & 100,0 a & $0,224 \mathrm{a}$ & 48,0 a \\
\hline CV (\%) & 12,8 & 12,6 & 11,4 \\
\hline
\end{tabular}

*Médias seguidas da mesma letra na coluna não diferem estatisticamente entre si, pelo teste de Tukey, a 5\% de probabilidade. 
TABELA 2- Médias das características de emergência de plântulas de araçá-boi submetidas a diferentes tempos de lixiviação. Manaus-AM, 2010.

\begin{tabular}{|c|c|c|c|c|}
\hline \multirow{2}{*}{$\begin{array}{c}\text { Período de } \\
\text { lixiviação (dia) }\end{array}$} & \multicolumn{4}{|c|}{ Características } \\
\hline & $\begin{array}{c}\text { Emergência } \\
(\%)\end{array}$ & $\begin{array}{l}\text { Tempo médio de } \\
\text { emergência (dia) }\end{array}$ & $\begin{array}{l}\text { Velocidade média de } \\
\text { emergência (dia) }\end{array}$ & $\begin{array}{l}\text { Velocidade de emergência } \\
\text { (planta/dia) }\end{array}$ \\
\hline 0 & $93,3 \mathrm{ab}$ & $106,8 \mathrm{ab}$ & $0,009 \mathrm{~b}$ & 0,099 bc \\
\hline 10 & 100,0 a & $80,3 \mathrm{ab}$ & $0,013 \mathrm{ab}$ & $0,139 a b$ \\
\hline 20 & $96,7 \mathrm{ab}$ & 83,5 ab & $0,012 \mathrm{ab}$ & $0,128 \mathrm{ab}$ \\
\hline 30 & $93,3 \mathrm{ab}$ & $79,0 \mathrm{ab}$ & $0,013 \mathrm{ab}$ & $0,132 \mathrm{ab}$ \\
\hline 40 & 100,0 a & 69,8 а & 0,015 a & 0,163 a \\
\hline 50 & 83,3 abc & $94,2 \mathrm{ab}$ & $0,011 \mathrm{ab}$ & 0,100 bc \\
\hline 60 & 70,0 bcd & $111,4 \mathrm{~b}$ & $0,009 \quad b$ & 0,068 с \\
\hline 70 & 73,3 abcd & $88,3 \mathrm{ab}$ & $0,012 \mathrm{ab}$ & 0,092 bc \\
\hline 80 & $60,0 \mathrm{~cd}$ & $96,5 \mathrm{ab}$ & $0,011 \mathrm{ab}$ & $0,067 \mathrm{c}$ \\
\hline 90 & $50,0 \mathrm{~d}$ & $102,0 \mathrm{ab}$ & $0,010 \mathrm{ab}$ & $0,056 \mathrm{c}$ \\
\hline CV (\%) & 11,4 & 14,5 & 15,4 & 19,6 \\
\hline
\end{tabular}

TABELA 3-Médias das características de emergência de plântulas de sementes fracionadas de araçá-boi. Manaus-AM, 2010.

\begin{tabular}{|c|c|c|c|c|}
\hline \multirow[t]{2}{*}{ Tratamentos } & \multicolumn{4}{|c|}{ Características } \\
\hline & $\begin{array}{c}\text { Plântula } \\
\text { normal (\%) }\end{array}$ & $\begin{array}{c}\text { Plântula } \\
\text { anormal (\%) }\end{array}$ & $\begin{array}{l}\text { Velocidade de emergência } \\
\text { (planta/dia) }\end{array}$ & $\begin{array}{c}\text { Tempo médio } \\
\text { de emergência } \\
\text { (dia) }\end{array}$ \\
\hline T1 - Sementes intactas (controle) & 90,0 a & $2,5 \mathrm{~b}$ & 0,085 a & $120,0^{\text {ns }}$ \\
\hline $\begin{array}{l}\text { T2 - Corte vertical } \\
\text { (lado da zona meristemática) }\end{array}$ & 95,0 a & $2,5 \mathrm{~b}$ & 0,095 a & 117,0 ns \\
\hline $\begin{array}{l}\text { T3 - Corte vertical } \\
\text { (lado oposto à zona meristemática) }\end{array}$ & $10,0 \mathrm{~b}$ & 25,0 a & $0,007 \mathrm{~b}$ & 107,0 ns \\
\hline $\begin{array}{l}\text { T4 - Corte horizontal } \\
\text { (lado da protuberância } \\
\text { meristemática) }\end{array}$ & 80,0 a & $5,0 \mathrm{~b}$ & $0,074 \mathrm{a}$ & $123,0^{\text {ns }}$ \\
\hline $\begin{array}{l}\text { T5 - Corte horizontal } \\
\text { (lado oposto à protuberância } \\
\text { meristemática) }\end{array}$ & $2,5 \mathrm{~b}$ & 20,0 a & $0,010 \mathrm{~b}$ & 99,0 ns \\
\hline CV (\%) & 19,9 & 21,9 & 22,2 & 22,2 \\
\hline
\end{tabular}

${ }^{1}$ Médias seguidas da mesma letra na coluna não diferem estatisticamente entre si, pelo teste de Tukey, a 5\% de probabilidade.

${ }^{2}$ As letras das médias de porcentagem de plântulas anormais foram trocadas para melhor visualização dos dados (maior porcentagem indesejável). 


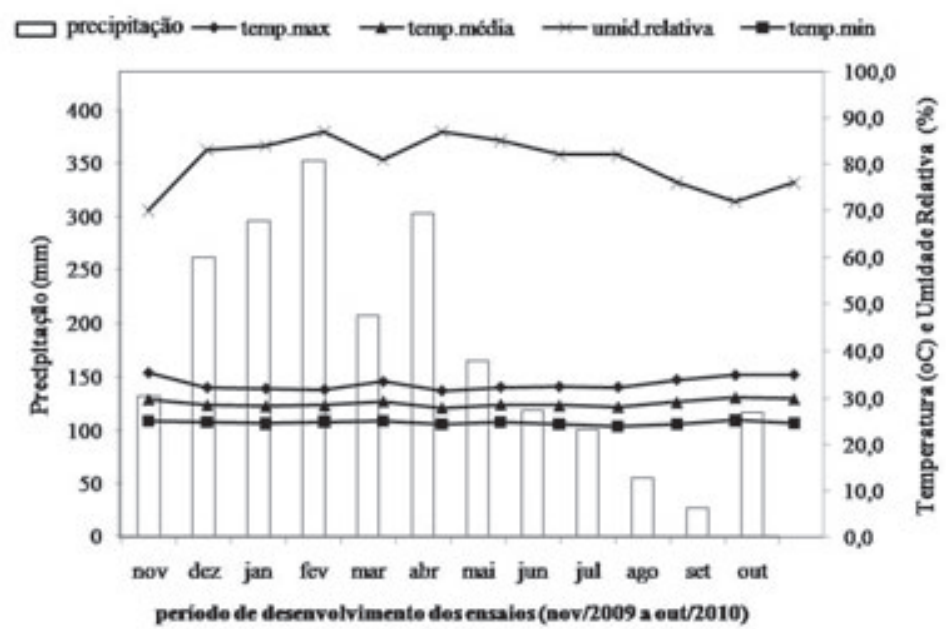

FIGURA 1- Dados de precipitação, umidade relativa e temperatura (média das máximas - temp. Máx, média das mínimas - temp. mín e média compensada - temp. média) durante o período de desenvolvimento dos experimentos com sementes de araçá-boi. Fonte: INMET (1 ${ }^{\circ}$ Distrito de Meteorologia - $1^{\circ}$ DISME/AM/AC/RR, Manaus - AM). Manaus-AM, 2010.

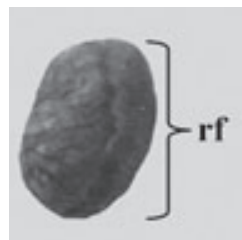

T1

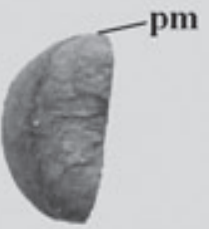

T2

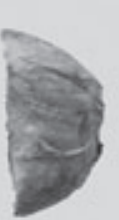

T3

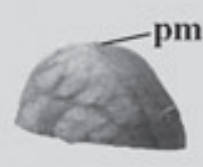

T4

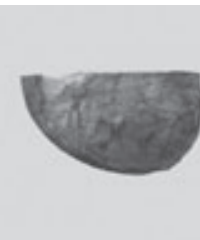

T5

FIGURA 2 - Posição do fracionamento das sementes de araçá-boi. T1 - sementes intactas; T2 - corte longitudinal (lado da rafe); T3 - corte longitudinal (lado oposto à rafe), T4 - corte transversal (lado da protuberância meristemática), T5 - corte transversal (lado oposto à protuberância meristemática). pm (área da protuberância meristemática), rf (rafe). Barra 1 cm. Manaus-AM, 2010.

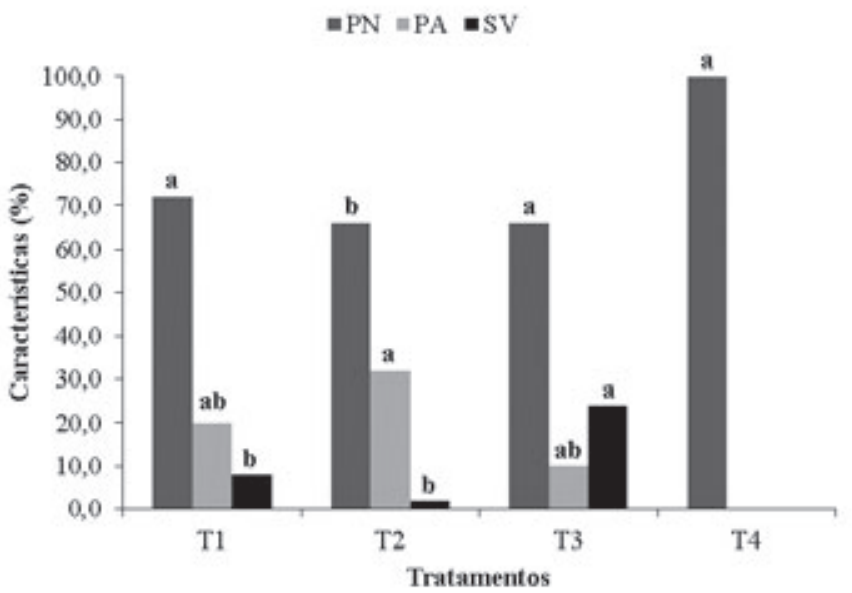

FIGURA 3- Características da emergência (\%) de sementes de araçá-boi aos 160 dias após a semeadura. PA (plântula anormal), PN (plântula normal) e SV (semente não germinada viável). T1 (Sementes intactas na casa de vegetação); T2 (Retirada parcial do tegumento na casa de vegetação); T3 (Sementes intactas no viveiro com 50\% sombreamento); T4 (Retirada parcial do tegumento no viveiro com 50\% sombreamento). Manaus-AM, 2010. 


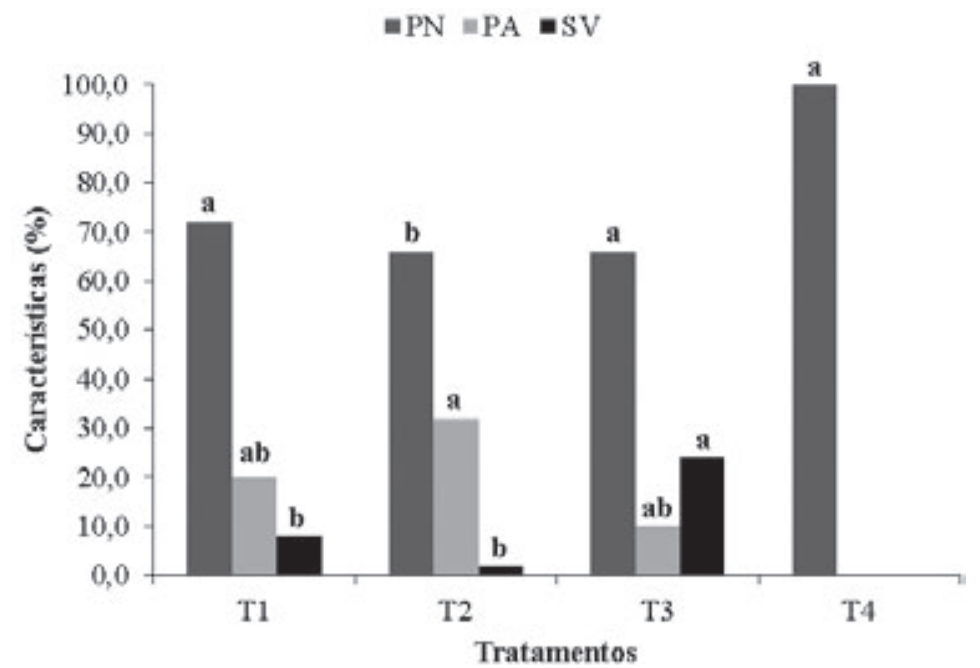

FIGURA 4- Teor de água das sementes de araçá-boi submetidas a diferentes tempos (dias) de lixiviação em água corrente. Manaus-AM, 2010.
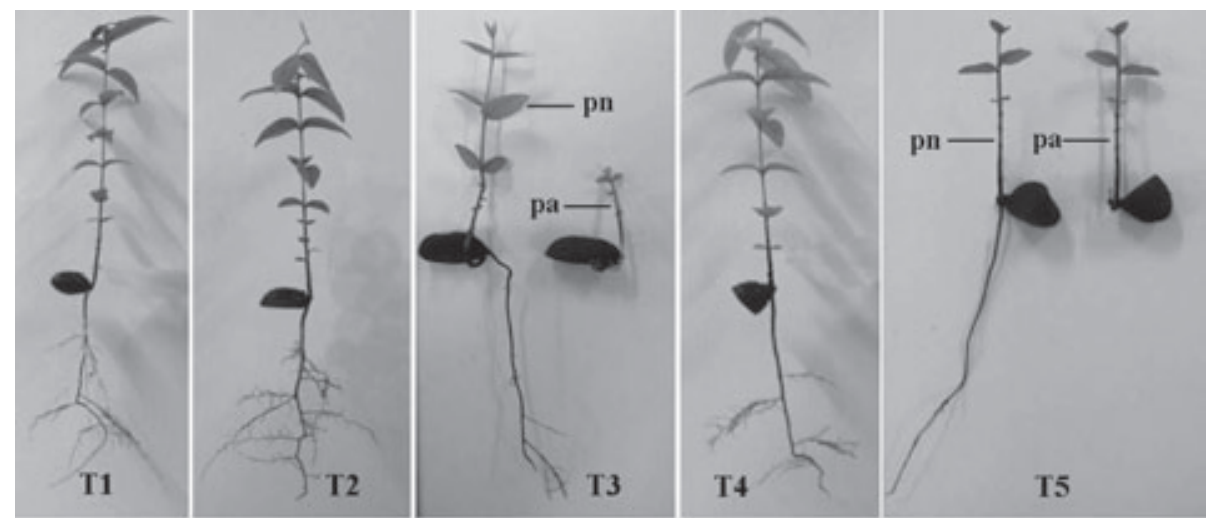

FIGURA 5 - Plântulas obtidas do fracionamento das sementes de araçá-boi. T1 - sementes intactas; T2 - corte longitudinal (lado da rafe); T3 - corte longitudinal (lado oposto à rafe); T4 - corte transversal (lado da protuberância meristemática);T5 - corte transversal (lado oposto à protuberância meristemática). bg (botão germinativo), pa (plântula anormal), pn (plântula normal).

\section{CONCLUSÕES}

1-A retirada parcial do tegumento das sementes de araçá-boi do lado da protrusão da raiz e da parte aérea diminui o tempo médio de germinação de 91 para 48 dias, com 100\% de emergência.

2-O ambiente de germinação influencia a formação de plântulas normais de araçá-boi, sendo o viveiro telado, com sombreamento de $50 \%$, o melhor ambiente.

3-As sementes de araçá-boi mantidas submersas em água corrente, por até 50 dias, mantêm a viabilidade e o vigor.

4-As frações de sementes que apresentam a protuberância meristemática originam plântulas normais na mesma porcentagem, velocidade e tempo médio de emergência que sementes intactas.
5-As frações que não apresentam a zona meristemática não são recomendadas para a produção de mudas, pois a porcentagem de plântulas anormais é elevada.

\section{AGRADECIMENTOS}

À Universidade Federal do Amazonas (UFAM), pelo curso de Pós-Graduação oferecido, e à Fundação de Amparo à Pesquisa do Estado do Amazonas (FAPEAM), pela concessão da bolsa. 


\section{REFERÊNCIAS}

ANJOS, A.M.G.; FERRAZ, I.D.K. Morfologia, germinação e teor de água das sementes de araçá-boi (Eugenia stipitata ssp. sororia). Acta Amazonica, Manaus, v.29, n.3, p.337-348, 1999.

BRASIL, Ministério da Agricultura, Pecuária e Abastecimento. Regras para análise de sementes. Brasília: Secretaria de Defesa Agropecuária,MAPA/ ACS, 2009. 339p.

CARDOSO, V.J.M. Dormência: estabelecimento do processo. In: FERREIRA, A. G.; BORGHETTI, F. Germinação: do básico ao aplicado. Porto Alegre: ARTMED, 2004. p. 95-108.

GENTIL, D.F.O.; FERREIRA, S.A.N. Viabilidade e superação da dormência em sementes de araçá-boi (Eugenia stipitata ssp. sororia). Acta Amazonica, Manaus, v.29, n.1, p.21-31, 1999.

JUSTO, C.F.; ALVARENGA, A.A. de; NERY, F.C.; DELU FILHO, N. Composição química, curva de embebição e efeito da temperatura sobre a germinação de sementes de Eugenia pyriformis Camb. (Myrtaceae). Revista Brasileira de Biociências, Porto Alegre, v.5, supl. 2, p. 510512, 2007.

MARTINOTTO, C.; PAIVA, R.; SANTOS, B.R.; SOARES, F.P.; NOUGUEIRA, R.C.; SILVA, A.A.N. Efeito da escarificação e luminosidade na germinação in vitro de sementes de cagaiteira (Eugenia dysenterica DC.). Ciência Agrotécnica, Lavras, v.31, n.6, p.1668-1671, 2007.

MENDES, A.M.S. Eugenia stipitata ssp. sororia McVaugh (araçá-boi) - Myrtaceae: abordagem fisiológica e morfoanatômica da semente, germinação e plântula. 2011. 117f. Tese de doutorado (Agronomia Tropical) - Faculdade de Ciências Agrárias, Universidade Federal do Amazonas, Manaus, 2011.

PIETROVSKI, E.F.; MAGINA, M.D.A.; GOMIG, F.; PIETROVSKI, C.F.; MICKE, G.A.; BARCELLOS, M.; PIZZOLATTI, M.G.; CABRINI, D.A.; BRIGHENTE, I.M.C.; OTUKI, M.F. Topical anti-inflammatory activity of Eugenia brasiliensis Lam. (Myrtaceae) leaves. Journal of Pharmacy and Pharmacology, London, v.60, n.4, p.479-487, 2008.
REYNERTSON, K.A.; YANG, H.; JIANG, B.; BASILE, M.J.; KENNELLY, E.J. Quantitative analysis of antiradical phenolic constituents from fourteen edible Myrtaceae fruits. Food Chemistry, London, v.109, n.4, p.883-890, 2008.

ROGEZ, H.; BUXANT, R.; MIGNOLET, E.; SOUZA, J.N.S.; SILVA, E.M.; LARONDELLE, Y. Chemical composition of the pulp of three typical Amazonian fruits: araçá-boi (Eugenia stipitata), bacuri (Platonia insignis), and cupuaçu (Theobroma grandiflorum). European Food Research and Technology, Berlin, v.218, p.380-384. 2004.

SANTANA, D.G.; RANAL, M.A. Análise da germinação - um enfoque estatístico. Brasília: Editora Universidade de Brasília, 2004. 248p.

SCALON, S.P.Q.; NEVES, E.M.S.; MASETO, T.E.; PEREIRA, Z.V. Sensibilidade à dessecação e ao armazenamento em sementes de Eugenia pyriformes Cambess. (uvaia). Revista Brasileira de Fruticultura, Jaboticabal, v.34, n.1, p.269-276, 2012.

SCHWARTZ, E.; FACHINELLO, J.C.; BARBIERI, R.L.; SILVA, J.B. Avaliação de populações de Butia capitata de Santa Vitória do Palmar. Revista Brasileira de Fruticultura, Jaboticabal, v.32, n.3, p.736-745, 2010.

SERT, M.A.; BONATO, C.M.; SOUZA, L.A. Germinação de sementes. In: SOUZA, L.A. (Org.). Sementes e plântulas: germinação, estrutura e adaptação. Ponta Grossa: Toda Palavra, 2009. p.91118.

SILVA, C.V.; BILIA, D.A.C.; BARBEDO, C.J. Fracionamento e germinação de sementes de Eugenia. Revista Brasileira de Sementes, Lavras, v.27, n.1, p.86-92, 2005.

SILVA, C.V.; BILIA, D.A.C.; MALUF, A.M.; BARBEDO, C.J. Fracionamento e germinação de uvaia (Eugenia pyriformis Cambess. - Myrtaceae). Revista Brasileira de Botânica, São Paulo, v.26, n.2, p.213-221, 2003. 